.
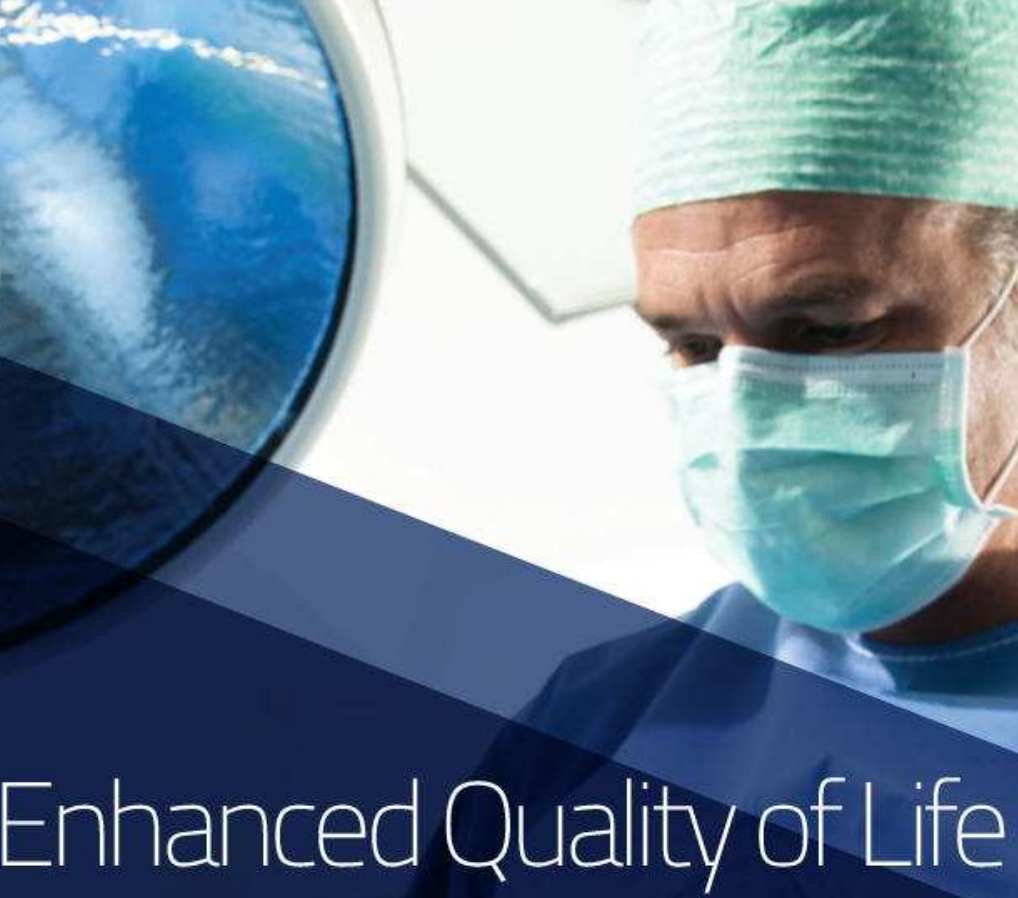

8
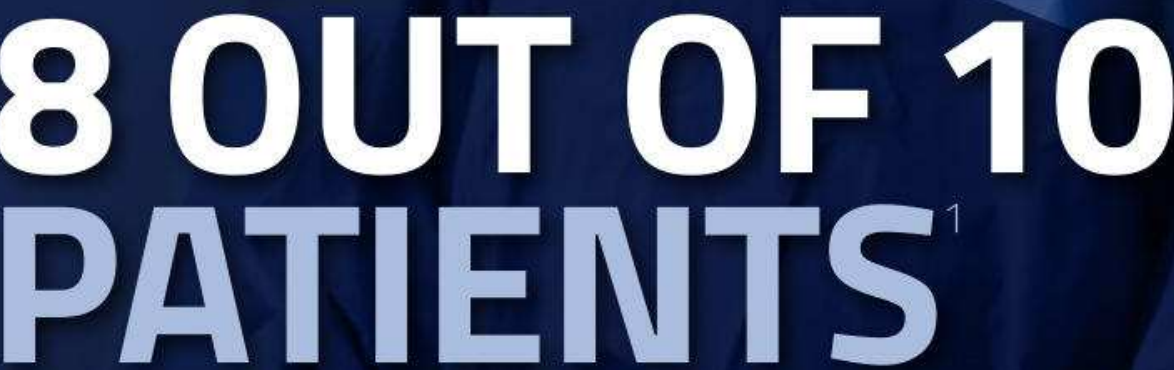

Experienced Improved Ejection Fraction ${ }^{2}$ or NYHA Heart Failure Class ${ }^{2}$ After a Protected PCI procedure with the Impella ${ }^{\circledR}$ Heart Pump

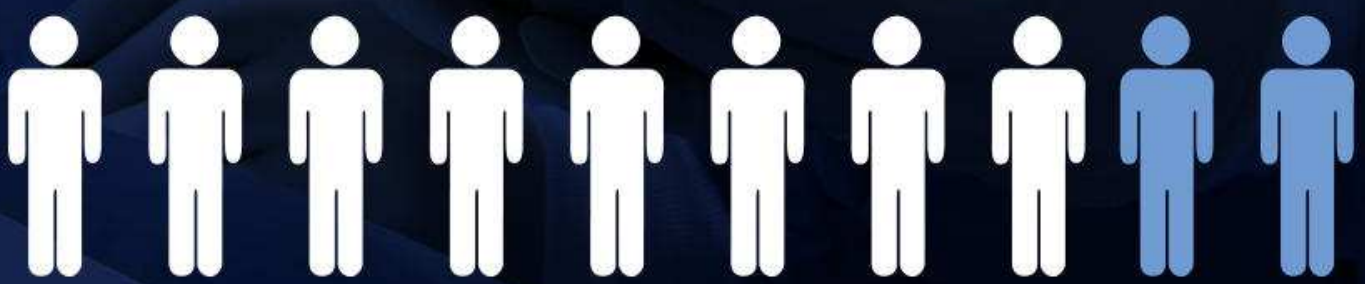

Learn more about Impella and how to build a Protected PCI program visit www.protectedpci.com 


\title{
Use and Misuse of Multivariable Approaches in Interventional Cardiology Studies on Drug-Eluting Stents: A Systematic Review
}

\author{
FABRIZIO D’ASCENZO, M.D., ${ }^{1}$ ERIKA CAVALLERO, M.D., ${ }^{1}$ GIUSEPPE BIONDI-ZOCCAI, M.D., ${ }^{2}$ \\ ClAUdio MORETTI, M.D., Ph.D., ${ }^{1}$ PIERLUIGI OMEDÈ, M.D., ${ }^{1}$ MARIO BOLlATI, M.D., ${ }^{1}$ \\ DAVIDE CASTAGNO, M.D., ${ }^{1}$ MARIA GRAZIA MODENA, M.D., ${ }^{2}$ FIORENZO GAITA, M.D., ${ }^{1}$ \\ and IMAD SHEIBAN, M.D. ${ }^{1}$
}

From the ${ }^{1}$ Division of Cardiology, University of Turin, Turin, Italy; and ${ }^{2}$ Division of Cardiology, University of Modena and Reggio Emilia, Modena, Italy

\begin{abstract}
Aims: Randomized clinical trials (RCTs) are the most reliable evidence, even if they require important resource and logistic efforts. Large, cost-free and real-world datasets may be easily accessed yielding to observational studies, but such analyses often lead to problematic results in the absence of careful methods, especially from a statistic point of view. We aimed to appraise the performance of current multivariable approaches in the estimation of causal treatment and effects in studies focusing on drug-eluting stents (DES).

Methods and Results: Pertinent studies published in the literature were searched, selected, abstracted, and appraised for quality and validity features. Six studies with a logistic regression were included, all of them reporting more than 10 events for covariates and different length of follow-up, with an overall low risk of bias. Most of the 15 studies with a Cox proportional hazard analysis had a different follow-up, with less than 10 events for covariates, yielding an overall low or moderate risk of bias. Sixteen studies with propensity score were included: the most frequent method for variable selection was logistic regression, with underlying differences in follow-up and less than 10 events for covariate in most of them. Most frequently, calibration appraisal was not reported in the studies, on the contrary of discrimination appraisal, which was more frequently performed. In seventeen studies with propensity and matching, the latter was most commonly performed with a nearest neighbor-matching algorithm yet without appraisal in most of the studies of calibration or discrimination. Balance was evaluated in $46 \%$ of the studies, being obtained for all variables in $48 \%$ of them.

Conclusions: Better exploitation and methodological appraisal of multivariable analysis is needed to improve the clinical and research impact and reliability of nonrandomized studies. (J Interven Cardiol 2012;25:611-621)
\end{abstract}

\section{Introduction}

Randomized clinical trials (RCTs) generate the most reliable clinical evidence, ${ }^{1}$ especially when combined within systematic reviews or meta-analyses. Despite these strengths, they deserve a critical appraisal ${ }^{2}$ about their methodological rigor, to stress their most relevant

Address for reprints: Dr. Fabrizio D'Ascenzo, Division of Cardiology, University of Turin, S. Giovanni Battista "Molinette" Hospital, Corso Bramante 88-90, 10126 Turin, Italy. Fax: 0016335419; e-mail: fabrizio.dascenzo@gmail.com limits like analysis of highly selected patients, subject attrition, and event adjudication.

Thus, also in interventional cardiology, still a high number of nonrandomized studies are performed in order to save economical resources, ${ }^{3}$ to create hypothesis, especially for nonrandomizable patients, or to shed light on the generalizability of results from existing randomized experiments. ${ }^{4}$

In the attempt to exploit the broad potential resources of observational databases, various statistical models are currently employed. Several different multivariable approaches are available to control for systematic 
D’ASCENZO, ET AL.

Table 1. Statistical Features of Studies with Logistic Regression

\begin{tabular}{|c|c|}
\hline $\begin{array}{l}\text { Studies } \\
\text { Time of Publication }\end{array}$ & $\begin{array}{c}N=6 \\
2007(2006-2009)\end{array}$ \\
\hline \multicolumn{2}{|l|}{ Study design } \\
\hline - Retrospective & $3(50 \%)$ \\
\hline - Prospective & $3(50 \%)$ \\
\hline \multicolumn{2}{|l|}{ Study organization } \\
\hline - One center & $3(50 \%)$ \\
\hline -Multicenter & $3(50 \%)$ \\
\hline \multicolumn{2}{|l|}{ Data source } \\
\hline -Clinical database & $6(100 \%)$ \\
\hline \multicolumn{2}{|l|}{ Follow-up } \\
\hline Similar & $3(50 \%)$ \\
\hline Nonsimilar & $3(50 \%)$ \\
\hline \multicolumn{2}{|l|}{ Censored data } \\
\hline Yes & $5(83 \%)$ \\
\hline No & $1(7 \%)$ \\
\hline \multicolumn{2}{|c|}{ Number of events for covariate } \\
\hline Less than 10 & $0(100 \%)$ \\
\hline \multicolumn{2}{|l|}{ Analytical bias } \\
\hline Low risk & $8(61 \%)$ \\
\hline Moderate risk & $5(39 \%)$ \\
\hline High or unclear risk & 0 \\
\hline \multicolumn{2}{|l|}{ Selection bias } \\
\hline Low risk & $2(14 \%)$ \\
\hline Moderate risk & $4(86 \%)$ \\
\hline \multicolumn{2}{|l|}{ Adjudication bias } \\
\hline Low risk & $3(50 \%)$ \\
\hline Moderate risk & $3(50 \%)$ \\
\hline \multicolumn{2}{|l|}{ Attrition bias } \\
\hline Low risk & $5(83 \%)$ \\
\hline Moderate risk & $1(7 \%)$ \\
\hline \multicolumn{2}{|l|}{ Overall credibility } \\
\hline Moderate & $4(86 \%)$ \\
\hline High & $2(15 \%)$ \\
\hline
\end{tabular}

baseline differences between groups naturally occurring in the nonrandomized setting. ${ }^{5}$ Even more their striking importance lies on defining the impact of several independent variables on a single dependent variable, thus avoiding confounding effects coming from observed variables in nonrandomized studies.

Nevertheless multivariable analysis should be performed according to precise statistical issues,${ }^{6-12}$ to assure accurate and understandable results, and to offer a more pregnant impact on everyday practice.

To our knowledge, no systematic review was performed to assess bulk and quality of multivariable approaches in observational studies, focusing on the comparison between drug-eluting stents (DES) versus bare metal stents (BMS) for percutaneous coronary intervention (PCI). Given this purpose, we explored the
Table 2. Statistical Features of Studies with Cox Proportional Hazard Analysis

\begin{tabular}{lc}
\hline Studies & $\mathrm{N}=15$ \\
Time of Publication & $2008(2008-2009)$ \\
\hline Study design & \\
$\quad$ - Retrospective & $7(46 \%)$ \\
$\quad$-Prospective & $8(54 \%)$ \\
Study organization & \\
- One center & $10(69 \%)$ \\
- Multicenter & $5(31 \%)$ \\
Data source & \\
-Clinical database & $15(100 \%)$ \\
Follow-up & \\
Similar & $2(12 \%)$ \\
Nonsimilar & $13(88 \%)$ \\
Censored data & \\
Yes & $14(94 \%)$ \\
No & $1(6 \%)$ \\
Number of events for covariate & \\
Less than 10 & $10(60 \%)$ \\
More than 10 & $4(24 \%)$ \\
Unclear & $1(6 \%)$ \\
Analytical bias & \\
Low risk & \\
Moderate risk & \\
Selection bias & \\
Low risk & \\
Moderate risk & $(74 \%)$ \\
Adjudication bias & $6(36 \%)$ \\
Low risk & \\
Moderate risk & \\
Unclear & $8(6 \%)$ \\
Attrition bias & $7(42 \%)$ \\
Low risk & \\
Moderate risk & \\
Unclear & $4(24 \%)$ \\
Overall credibility & $8(48 \%)$ \\
Moderate & $3(18 \%)$ \\
High & \\
Very high & $3(18 \%)$ \\
\hline & $9(54 \%)$ \\
\hline
\end{tabular}

methodological structure of articles, assessed how often authors explicitly faced the topic of internal validity, tested the risk for different bias, and, finally, aimed to propose a score to summarize the overall credibility of nonrandomized studies

\section{Methods}

PubMed was searched for pertinent articles published between January 2002 (when DES were first marketed worldwide) and December 2010 in keeping with established methods, ${ }^{13}$ searching for: 


\section{MULTIVARIABLE APPROACH IN DRUG-ELUTING STENT STUDIES}

Table 3. Statistical Features of Studies with Propensity Score

\begin{tabular}{|c|c|}
\hline $\begin{array}{l}\text { Studies } \\
\text { Time of Publication }\end{array}$ & $\begin{array}{c}N=16 \\
2008(2008-2009)\end{array}$ \\
\hline \multicolumn{2}{|l|}{ Study design } \\
\hline Retrospective & $5(32 \%)$ \\
\hline Prospective & $11(68 \%)$ \\
\hline \multicolumn{2}{|l|}{ Study organization } \\
\hline One center & $10(63 \%)$ \\
\hline Multicenter & $6(37 \%)$ \\
\hline \multicolumn{2}{|l|}{ Data source } \\
\hline Clinical database & $14(84 \%)$ \\
\hline Institutional database & $2(16 \%)$ \\
\hline \multicolumn{2}{|l|}{ Follow-up } \\
\hline Similar & $2(12 \%)$ \\
\hline Nonsimilar & $14(84 \%)$ \\
\hline \multicolumn{2}{|l|}{ Censored data } \\
\hline Yes & $13(76 \%)$ \\
\hline No & $3(24 \%)$ \\
\hline \multicolumn{2}{|l|}{ Number of events for covariate } \\
\hline Less than 10 & $5(30 \%)$ \\
\hline More than 10 & $11(70 \%)$ \\
\hline \multicolumn{2}{|l|}{ Methods to select variables } \\
\hline Logistic regression model & $16(100 \%)$ \\
\hline \multicolumn{2}{|l|}{ Variables inserted according to } \\
\hline Nonparsimonious & $7(42 \%)$ \\
\hline Selected variables & $11(68 \%)$ \\
\hline $\begin{array}{l}\text { Propensity score included in Cox mul- } \\
\text { tivariable analysis. }\end{array}$ & $5(30 \%)$ \\
\hline \multicolumn{2}{|l|}{ Discrimination appraisal } \\
\hline Not reported & $6(48 \%)$ \\
\hline $\begin{array}{l}\text { Reported (median and third quartiles } \\
\text { of c-index) }\end{array}$ & $\begin{array}{c}10(52 \%) \\
0.87(0.82-0.86)\end{array}$ \\
\hline \multicolumn{2}{|l|}{ Calibration appraisal } \\
\hline Not reported & $9(48 \%)$ \\
\hline $\begin{array}{l}\text { Reported not significant according to } \\
\text { Hosmer-Lemeshow test }\end{array}$ & $7(42 \%)$ \\
\hline \multicolumn{2}{|l|}{ Collinearity appraisal } \\
\hline Not reported & $16(100 \%)$ \\
\hline \multicolumn{2}{|l|}{ Analytical bias } \\
\hline Low risk & $10(64 \%)$ \\
\hline Moderate risk & $6(36 \%)$ \\
\hline \multicolumn{2}{|l|}{ Selection bias } \\
\hline Low risk & $9(54 \%)$ \\
\hline Moderate risk & $6(36 \%)$ \\
\hline Unclear & $1(6 \%)$ \\
\hline \multicolumn{2}{|l|}{ Adjudication bias } \\
\hline Low risk & $7(42 \%)$ \\
\hline Moderate risk & $6(36 \%)$ \\
\hline Unclear & $3(18 \%)$ \\
\hline \multicolumn{2}{|l|}{ Attrition bias } \\
\hline Low risk & $3(18 \%)$ \\
\hline Moderate risk & $9(54 \%)$ \\
\hline Unclear & $3(18 \%)$ \\
\hline \multicolumn{2}{|l|}{ Overall credibility } \\
\hline Moderate & $12(82 \%)$ \\
\hline High & $2(12 \%)$ \\
\hline Very high & $1(6 \%)$ \\
\hline
\end{tabular}

- DES and BMS* and multivariate analysis

- DES and BMS* and multivariable methods

- DES and BMS* and logistic regression

- DES and BMS* and Cox proportional hazard analysis

- DES and BMS* and propensity score

- DES and BMS* and propensity score with matching

Study Selection. Retrieved citations were first screened independently by 2 reviewers (G.B.-Z, F.DA.) at the title and/or abstract level, with divergences resolved after consensus. If potentially pertinent, they were then appraised as complete reports according to the following explicit selection criteria, which were piloted over the first 5 cases for consistency and discrimination. Inclusion criteria were (all had to be met for inclusion): (i) human studies, with nonrandomized design (ii) investigating patients undergoing PCI, with implantation of DES and BMS, and (iii) employing multivariable approaches. Exclusion criteria were (any one alone was enough for exclusion): (i) nonhuman setting and (ii) RCT design. No dimensional cut off in terms of included patients was used, to offer a wide representation of interventional studies.

Data Extraction. The following data were abstracted by 2 unblinded independent reviewers (G.B.Z, F.DA.) on prespecified forms, which were piloted over the first 5 cases for consistency and discrimination, with divergences resolved after consensus. In particular, authors, journal, year of publication, location of the study group were first assessed, and impact on death, myocardial infarction (MI), repeat revascularization, or their composite, namely major adverse cardiac events (MACE).

Statistical Methods Appraisal. Studies responding to inclusion criteria were divided according to their multivariable approaches ${ }^{12}$ in logistic regression, Cox proportional hazard analysis, propensity score and propensity score with matching. First, for all of these studies evaluation of difference in follow-up length, presence of censored data, and number of events per covariates was performed. Then, for studies with propensity score adjustment, we analyzed methods for variable selection, prediction, discrimination, calibration collinearity, and use of parsimonious or not approach. ${ }^{8}$ Then, if matching was present, matching methods and balance were also analyzed. 
D’ASCENZO, ET AL.

Table 4. Statistical Features of Studies with Propensity Score with Matching

\begin{tabular}{|c|c|}
\hline $\begin{array}{l}\text { Studies } \\
\text { Time of Publication }\end{array}$ & $\begin{array}{c}N=17 \\
2008(2007-2009)\end{array}$ \\
\hline \multicolumn{2}{|l|}{ Study design } \\
\hline Retrospective & $7(45 \%)$ \\
\hline Prospective & $10(55 \%)$ \\
\hline \multicolumn{2}{|l|}{ Study organization } \\
\hline One center & $12(75 \%)$ \\
\hline Multicenter & $5(25 \%)$ \\
\hline \multicolumn{2}{|l|}{ Data source } \\
\hline Clinical database & $15(79 \%)$ \\
\hline Institutional database & $2(11 \%)$ \\
\hline \multicolumn{2}{|l|}{ Follow-up } \\
\hline Similar & $2(11 \%)$ \\
\hline Nonsimilar & $15(79 \%)$ \\
\hline \multicolumn{2}{|l|}{ Censored data } \\
\hline Yes & $17(100 \%)$ \\
\hline \multicolumn{2}{|l|}{ Number of events for covariate } \\
\hline Less than 10 & $9(55 \%)$ \\
\hline More than 10 & $8(45 \%)$ \\
\hline \multicolumn{2}{|l|}{ Methods to select variables } \\
\hline Logistic regression model & $15(79 \%)$ \\
\hline Unclear & $2(21 \%)$ \\
\hline \multicolumn{2}{|l|}{ Variables inserted according to } \\
\hline Nonparsimonious & $3(16 \%)$ \\
\hline Selected variables & $13(64 \%)$ \\
\hline Unclear & $1(5.5 \%)$ \\
\hline $\begin{array}{l}\text { Propensity score included in Cox } \\
\text { multivariable analysis }\end{array}$ & $3(16 \%)$ \\
\hline \multicolumn{2}{|l|}{ Matching method } \\
\hline $\begin{array}{l}\text { Nearest-neighbor-matching } \\
\text { algorithm }\end{array}$ & $14(78 \%)$ \\
\hline Quintiles & $2(12 \%)$ \\
\hline Unclear & $1(6 \%)$ \\
\hline \multicolumn{2}{|l|}{ Balance assessment } \\
\hline $\begin{array}{l}\text { Performed, with differences less than } \\
10 \%\end{array}$ & $6(40 \%)$ \\
\hline Performed, with differences less than 5\% & $1(6 \%)$ \\
\hline Unclear & $6(54 \%)$ \\
\hline \multicolumn{2}{|l|}{ Balance achieved for } \\
\hline All variables & $8(48 \%)$ \\
\hline \multicolumn{2}{|l|}{ All except } \\
\hline 口 1 variable & $1(6 \%)$ \\
\hline $\mathbf{Z} 2$ variables & $1(6 \%)$ \\
\hline $\mathbf{a}$ variables & $1(6 \%)$ \\
\hline प variables & $2(12 \%)$ \\
\hline 8 variables & $1(6 \%)$ \\
\hline Nonreported & $3(18 \%)$ \\
\hline \multicolumn{2}{|l|}{ Discrimination appraisal } \\
\hline Not reported & $11(63 \%)$ \\
\hline $\begin{array}{l}\text { Reported (median and third quartiles } \\
\text { of c-index) }\end{array}$ & $6(37 \%)$ \\
\hline \multicolumn{2}{|l|}{ Calibration appraisal } \\
\hline Not reported & $15(89 \%)$ \\
\hline \multirow{2}{*}{ Hosmer-Lemeshow test } & $2(11 \%)$ \\
\hline & $073(071-076)$ \\
\hline
\end{tabular}

Table 4. Continued.

\begin{tabular}{lc}
\hline Studies & $\mathrm{N}=17$ \\
Time of Publication & $2008(2007-2009)$ \\
\hline Collinearity appraisal & \\
$\quad$ Not reported & $14(78 \%)$ \\
Reported, without reporting high correlation & $3(22 \%)$ \\
Analytical bias & \\
$\quad$ Low risk & $13(78 \%)$ \\
$\quad$ Moderate risk & $4(22 \%)$ \\
Selection bias & \\
Low risk & $7(42 \%)$ \\
Moderate risk & $10(58 \%)$ \\
Adjudication bias & \\
Low risk & $7(42 \%)$ \\
Moderate risk & $9(52 \%)$ \\
Unclear & $1(6 \%)$. \\
Attrition bias & \\
Low risk & $5(30 \%)$ \\
Moderate risk & $8(48 \%)$ \\
Unclear & $2(12 \%)$ \\
Overall credibility & \\
Moderate & $9(54 \%)$ \\
High & $6(36 \%)$ \\
Very high & $2(10 \%)$ \\
\hline
\end{tabular}

Internal Validity and Quality Appraisal. The quality of included studies was appraised by unblinded independent reviewers (G.B.-Z, F.DA.), on prespecified forms, which were piloted over the first 5 cases for consistency and discrimination, with divergences resolved after consensus. Modifying the MOOSE (Metaanalysis of Observational Studies in Epidemiology) items to take into account the specific features of included studies, ${ }^{4}$ we separately abstracted and appraised study design, setting, data source, and statistical methods for multivariable analysis, as well as risk of analytical, selection, adjudication, detection, and attrition bias (expressed as low, moderate, or high risk of bias, as well as incomplete reporting leading to inability to ascertain the underlying risk of bias). Moreover, we appraised the overall credibility of short listed studies, to summarize the previous features. Zero points were assigned for retrospective design and single-center setting, 1 for prospective design and for a multicenter setting. Moreover, 2 points were ascribed for overall low risk of bias, 1 for moderate risk, and zero for high or unclear risk. If the sum of these scores was 10, a very high credibility was granted; if it was between 7 and 9, high; 4 and 6, moderate; 1 and 3, low; 0 , very low (e.g., a multicenter study with prospective design, with low risk of analytical bias, medium risk of selection bias, low of attrition bias, medium of adjudication 


\section{MULTIVARIABLE APPROACH IN DRUG-ELUTING STENT STUDIES}

bias totally scored 9, thus with high credibility; for further details, see Table S1). Moreover, for studies with propensity score and with propensity score with matching, distribution of statistical features among studies with moderate and high quality, and among studies in different quartiles of Impact Factor (IF; CI 95\%) was evaluated.

Data Analysis and Synthesis. Continuous variables are reported as mean (standard deviation) or median (range). Categorical variables are expressed as $\mathrm{n} / \mathrm{N}(\%)$. No formal test of hypothesis was employed given the exploratory and hypothesis generating scope of our systematic review.

\section{Results}

Fifty-eight studies were initially analyzed: 3 were excluded for reporting only multivariable analysis results, ${ }^{14-16} 2$ because reporting only predictors of stent thrombosis, ${ }^{17,18} 3$ because noncomparing directly BMS and DES ${ }^{19-22}$; finally 50 studies were included (Fig. 1).

Six studies with a logistic regression were included, ${ }^{23-28}$ all of them reporting more than 10 events for covariates and different length of follow-up, with an overall low risk of bias (Table 1). Logistic regression did not modify results of univariate analysis. (Fig. 2).

Fifteen studies with a Cox proportional hazard anal$y \operatorname{sis}^{25,29-42}$ are described in Table 2. Eighty-eight percent of them had different follow-up, $94 \%$ censored data and $60 \%$ reported less than 10 events for covariates. An overall low or moderate risk of bias was appraised. At multivariate analysis, superiority for DES in reducing myocardial infarction and death was less frequently reported (Fig. 3).

Sixteen studies with propensity score were analyzed $^{34,42-56}$ (Table 3). Logistic regression was always used for variable selection; $84 \%$ of them reported differences in follow-up, $70 \%$ more than 10 events for covariate and a nonparsimonious method of variable selection was noted in $42 \%$ of cases. Both calibration and discrimination appraisal were reported in 52\% of the studies; moreover, propensity score was inserted in Cox multivariable analysis in $30 \%$ of cases. Overall analysis showed no differences between BMS and DES, after multivariable analysis in most cases for death and myocardial infarction (Fig. 4).

In the 17 included studies, ${ }^{57-73}$ matching was performed with a nearest neighbor-matching algorithm in
$78 \%$ of cases (Table 4). Variables were inserted with a nonparsimonious method in $16 \%$ of cases, and balance was evaluated in $46 \%$ of studies, being obtained for all variables in $48 \%$ of them; discrimination was reported in $37 \%$ and calibration in $11 \%$ of cases. Myocardial infarction and death trended to change, the former without differences between BMS and DES after propensity score with matching, the latter showing a tendency to better outcome after stenting with DES (Fig. 5).

Interestingly, both after appraisal for IF and quality differences only small differences were found for propensity score with matching about discrimination, calibration, and balance evaluation among different classes (Figs. 6, 7 and 8). On the contrary, for propensity scores studies within the highest quartiles of IF, calibration and discrimination were most frequently reported.

\section{Discussion}

The present review originally shows for the first time that the application of complex multivariable methods is becoming increasingly popular in nonrandomized medical research. Yet, statistical analyses of these studies often lack internal appraisal and validation, a finding approximately independent from the rating of the journal in which the studies were published. Evaluation of the methodological quality of such studies through a synthetic score is feasible and appears important for a critical approach to medical literature.

Because of great economical and medical policy changes ${ }^{3}$ observational studies will gain room in scientific research, and the next era has indeed been defined as the time of comparative-effectiveness research. RCTs remain the leading evidence; being burdened from several economical, logistic, and temporal hurdles, these costs cannot generate bias-free information anyway. ${ }^{74-76}$ Moreover, given the international economic scenario and the growing role of conflict of interest in data interpretation, ${ }^{77,78}$ researchers ought to develop new tools to prevent problems affecting the accuracy and interpretation of results obtained from widely available observational datasets. As a matter of fact, such a kind of methodological problem would make the reported results potentially inaccurate, misleading, or difficult to interpret.

From our review of current literature, multivariable analysis is the reference method to explore observational information equally in its different approaches 
D’ASCENZO, ET AL.

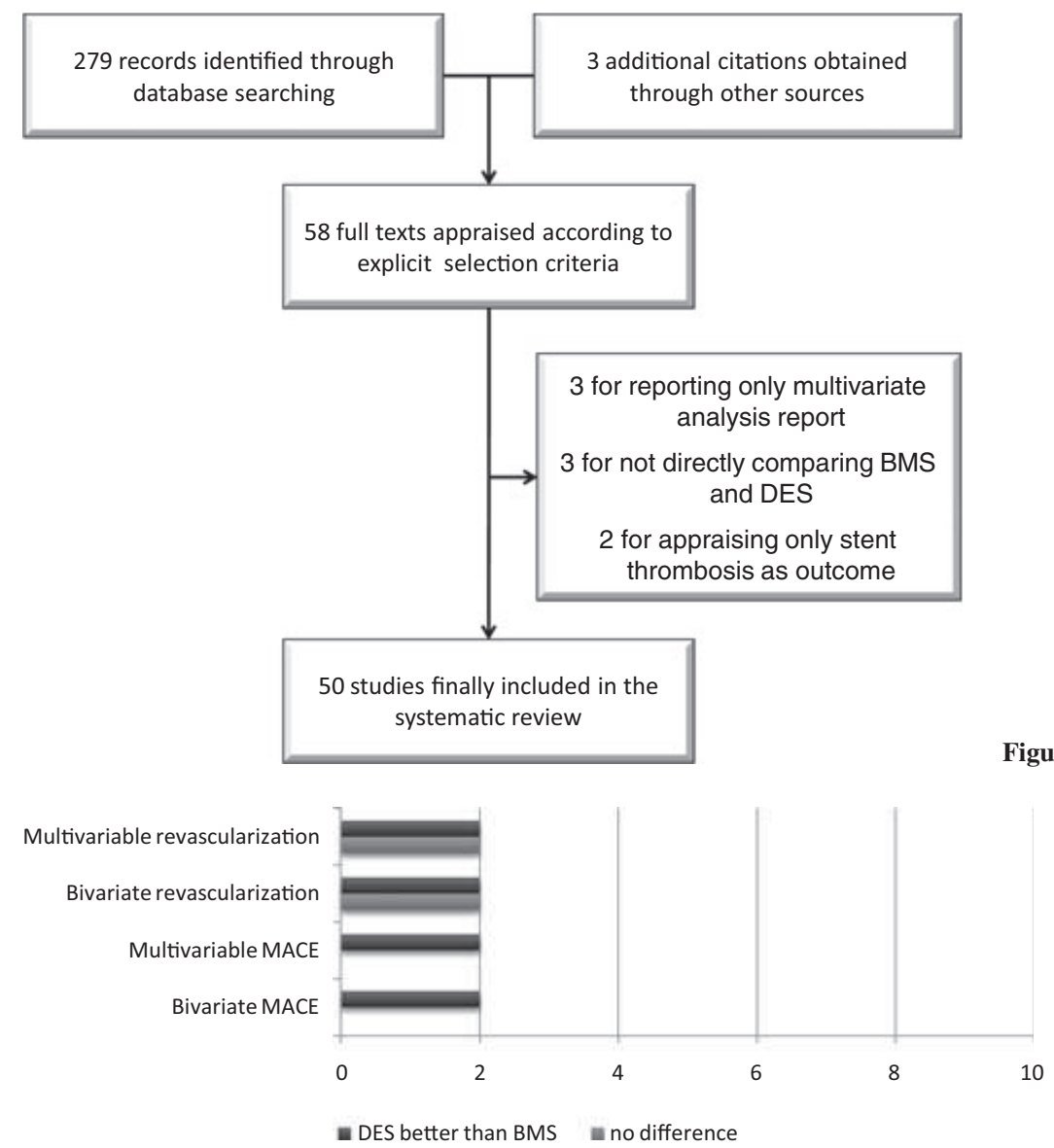

Figure 2. Performance of logistic regression studies. $(\mathrm{DES}=$ Drug-eluting stent; BMS $=$ Bare metal stent). Red lines represented studies reporting first at univariate, then at multivariate analysis, a significant better outcome for DES, blue lines for BMS.

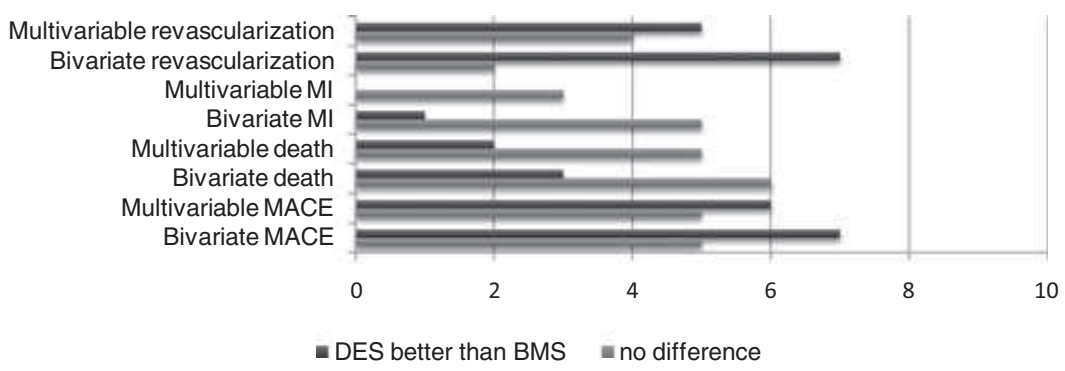

Figure 3. Performance of Cox proportional hazard analysis studies. Red lines represented studies reporting first at univariate, then at multivariate analysis, a significant better outcome for DES, blue lines for BMS.

(logistic regression, Cox proportional hazard analysis, propensity score, or propensity score with matching and multiple logistic regression). All the examined statistical methods tend to approach observational studies results to meta-analysis outcomes: actually BMS did not show, after multivariable approaches, a detrimental effect on survival, as demonstrated in 2 recent systematic reviews. ${ }^{79,80}$ Thus, to give more statistical significance to this analysis, it is worthwhile to critically appraise and develop their internal validity, both for the point of view of reducing risk of bias and for the point of view of statistical analysis. ${ }^{8-11}$ Actually, as with all scientific models the results require validation to ensure protection against unrecognized problems and limitations.

Unfortunately, our results underline an overall moderate risk of adjudication and attrition bias, while the risk of selection and analytical bias seemed less pronounced. The chance to overcome adjudication- and attrition-related pitfalls may lie in example in a more 


\section{MULTIVARIABLE APPROACH IN DRUG-ELUTING STENT STUDIES}

Figure 4. Performance of propensity score studies. Red lines represented studies reporting first at univariate, then at multivariate analysis, a significant better outcome for DES, blue lines for BMS.

Figure 5. Performance of propensity score studies with matching. Red lines represented studies reporting first at univariate, then at multivariate analysis, a significant better outcome for DES, blue lines for BMS.
Figure 6. Discrimination and calibration appraisal according to Impact factor of propensity studies. Four were included in the lowest quartile (with an IF $<2.80$ ), four in the highest (IF > 6.80), and four with IF between previous values. Four studies were inserted in not impacted Journal.
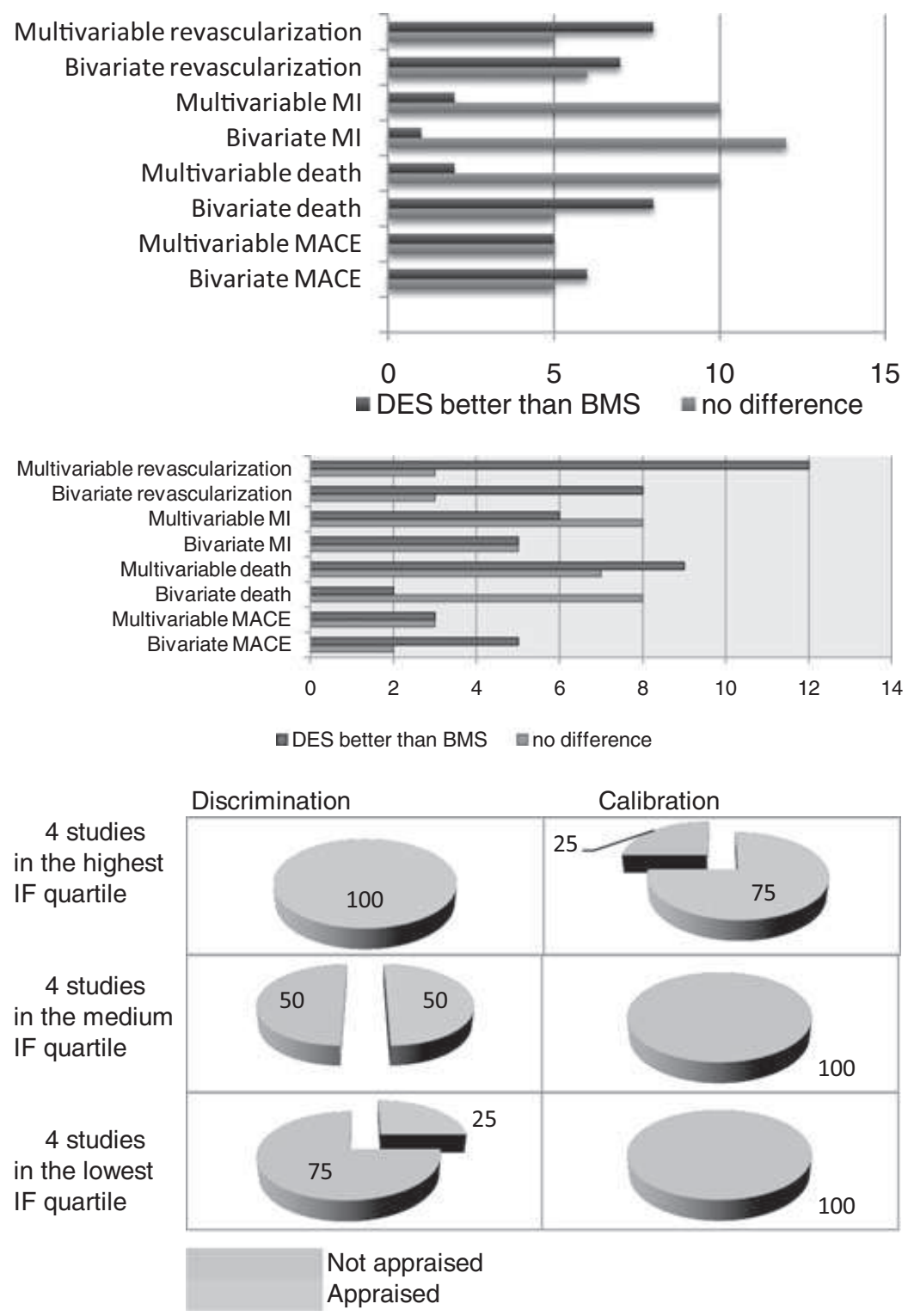

Finally, omission of the methodological assessment was not related to quality rating of the journal in which the paper was published: we found no substantial differences among studies stratified according to journal of publication IF, thus stressing also more careful attention from peer reviewers in studies reporting multivariable adjustments.

The main implication of our remarks is a call for researchers to improve the reports about their statistical analysis with care for internal validation and methodological assessment. Our score may be useful to fulfill 
D’ASCENZO, ET AL.
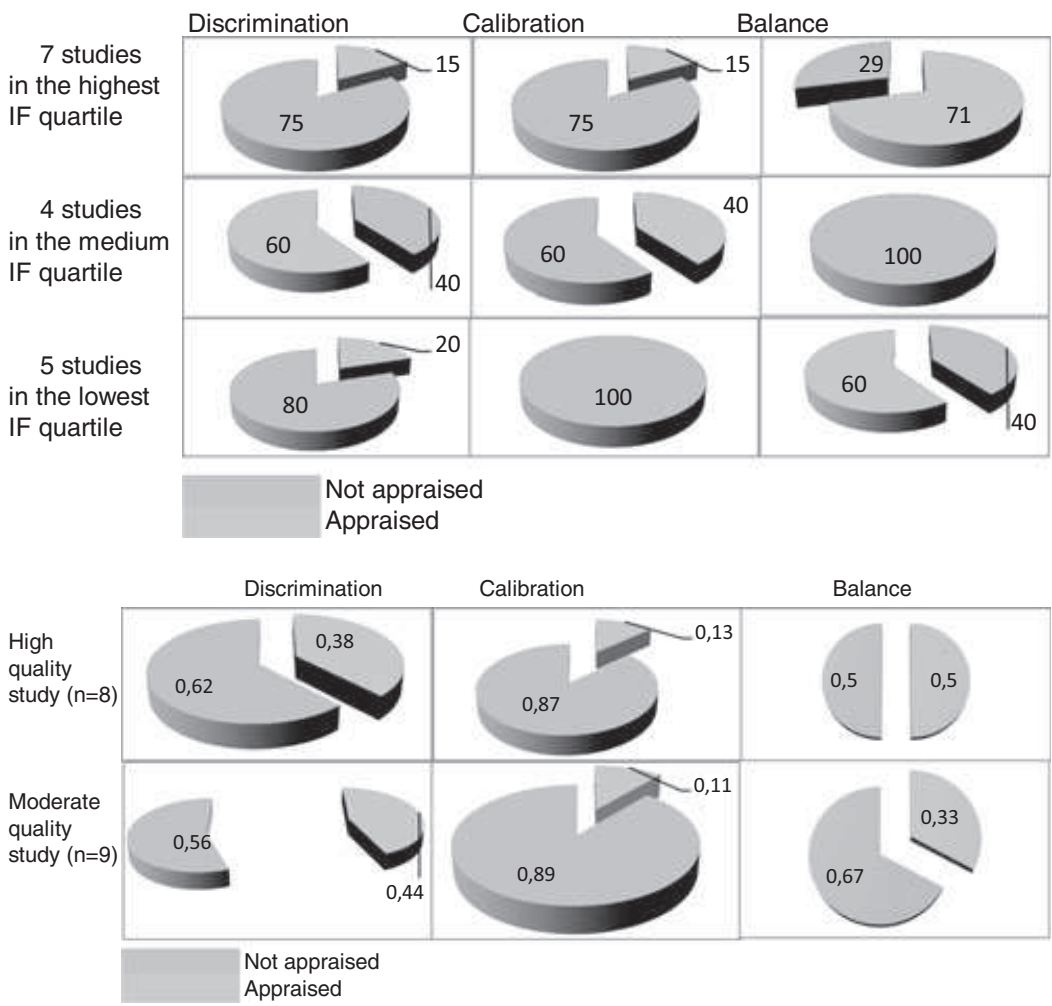

Figure 7. Discrimination, calibration and balance appraisal according to Impact factor of propensity studies with matching. Five were included in the lowest quartile (with an $\mathrm{IF}<5.24)$, seven in the highest (IF > 14.82) and four with IF between previous values. One study was inserted in not impacted Journal.

Figure 8. Discrimination, calibration, and balance appraisal according to propensity score with matching studies' quality.

this aim, helping investigators and reviewers to guide and correct themselves.

Possible limitation of the present investigation is the variety of involved studies that broadly differ in the number of patients included, follow-up length, and year of publication. Anyway, we consider these limitations avenues for further research because it would be interesting to evaluate the methodological quality of medical research in relation to study dimensions and the period of realization.

In summary, multivariate analysis is spreading around in medical literature, and as a useful tool to exploit observational data it needs a more detailed internal control. For readers, clinicians, and researchers a simple assessment of methodology is fundamental to drive critical and conscious employment of scientific information.

\section{References}

1. Biondi-Zoccai GGL, Agostoni P, Abbate A. Parallel hierarchy of scientific studies in cardiovascular medicine. Ital Heart $\mathrm{J}$ 2003;4:819-820.

2. Schulz KF, Altman DG, Moher D; CONSORT Group. CONSORT 2010 statement: Updated guidelines for reporting parallel group randomised trials. BMJ 2010;340:c332. doi 10.1136/bmj.c332.

3. Obama B. Modern health care for all Americans. N Engl J Med 2008;359(15):1537-1541. [Epub 2008 Sep 24. No abstract available].

4. Stroup DF, Berlin JA, Morton SC, et al. Meta-analysis of observational studies in epidemiology: A proposal for reporting. Meta-analysis Of Observational Studies in Epidemiology (MOOSE) group. JAMA 2000;283(15):2008-2012

5. Katz MH. Multivariable Analysis: A Practical Guide for Clinicians. New York: Cambridge University Press, 2006.

6. Concato J, Feinstein AR, Holford TR. The risk of determining risk with multivariable models. Ann Intern Med 1993;118: 201-210.

7. Weitzen S, Lapane KL, Toledano AY, et al. Principles for modeling propensity scores in medical research: A systematic literature review. Pharmacoepidemiol Drug Saf 2004;13:841-853.

8. Weitzen S, Lapane KL, Toledano AY, et al. Weaknesses of goodness-of-fit tests for evaluating propensity score models: The case of the omitted confounder. Pharmacoepidemiol Drug Saf 2005;14:227-238.

9. Austin PC. Some methods of propensity-score matching had superior performance to others: Results of an empirical investigation and Monte Carlo simulations. Biom J 2009;51:171-184.

10. Austin PC. The performance of different propensity-score methods for estimating relative risks. J Clin Epidemiol 2008;61:537-545.

11. Rubin DB. Estimating causal effects from large data-sets using propensity scores. Ann Intern Med 1997;127:757-763.

12. Biondi-Zoccai G, Romagnoli E, Agostoni P, et al. Are propensity scores really superior to standard multivariable analysis? Contemp Clin Trials 2011;32(5):731-740. 


\section{MULTIVARIABLE APPROACH IN DRUG-ELUTING STENT STUDIES}

13. Wilczynski NL, Haynes RB, for the Hedges Team. Developing optimal search strategies for detecting clinically sound prognostic studies in MEDLINE: An analytic survey. BMC Med 2004;2:23.

14. Kukreja N, Onuma Y, Garcia-Garcia H, et al. Primary percutaneous coronary intervention for acute myocardial infarction: Long-term outcome after bare metal and drug-eluting stent implantation. Circ Cardiovasc Interv 2008;1(2):103-110. [Epub 2008 Sep 3].

15. Kukreja N, Onuma Y, Garcia-Garcia HM, et al. Interventional Cardiologists of the Thoraxcenter (2000 to 2005). The risk of stent thrombosis in patients with acute coronary syndromes treated with bare-metal and drug-eluting stents. JACC Cardiovasc Interv 2009;2(6):534-541.

16. Ma HY, Zhou YJ, Dick RJ, et al. Long-term outcome of patients of over 85 years old with acute coronary syndrome undergoing percutaneous coronary stenting: A comparison of bare metal stent and drug eluting stent. Chin Med J (Engl) 2008;121(10):887-891.

17. Hoffmann R, Klinker H, Adamu U, et al. The risk of definitive stent thrombosis is increased after "off-label" stent implantation irrespective of drug-eluting stent or bare-metal stent use. Clin Res Cardiol 2009;98(9):549-554. [Epub 2009 Aug 11].

18. Aoki J, Lansky AJ, Mehran R, et al. Early stent thrombosis in patients with acute coronary syndromes treated with drug-eluting and bare metal stents: The Acute Catheterization and Urgent Intervention Triage Strategy trial. Circulation 2009;119(5):687-698. [Epub 2009 Jan 26].

19. Andron M, Perry RA, Egred M, et al. The impact of diabetes mellitus on two-year mortality following contemporary percutaneous coronary intervention: Implications for revascularization practice. J Interv Cardiol 2009;22(5):420-426. [Epub 2009 May 7].

20. De Labriolle A, Bonello L, Lemesle G, et al. Clinical presentation and outcome of patients hospitalized for symptomatic in-stent restenosis treated by percutaneous coronary intervention: Comparison between drug-eluting stents and bare-metal stents. Arch Cardiovasc Dis 2009;102(3):209-217. [Epub 2009 Mar 17].

21. Dzavík V, Buller CE, Devlin G, et al. Angiographic and clinical outcomes of drug-eluting versus bare metal stent deployment in the Occluded Artery Trial. Catheter Cardiovasc Interv 2009;73(6):771-779.

22. Rathore S, Kinoshita Y, Terashima M, et al. A comparison of clinical presentations, angiographic patterns and outcomes of in-stent restenosis between bare metal stents and drug eluting stents. EuroIntervention 2010;5(7):841-846.

23. Assali A, Raz Y, Vaknin-Assa H, et al. Beneficial 2-years results of drug-eluting stents in saphenous vein graft lesions. EuroIntervention 2008;4(1):108-114.

24. Maresta A, Varani E, Balducelli M, et al; DESSERT Investigators. Comparison of effectiveness and safety of sirolimuseluting stents versus bare-metal stents in patients with diabetes mellitus (from the Italian Multicenter Randomized DESSERT Study). Am J Cardiol 2008;101(11):1560-1566. [Epub 2008 Apr 11].

25. De Felice F, Fiorilli R, Parma A, et al. 3-year clinical outcome of patients with chronic total occlusion treated with drug-eluting stents. JACC Cardiovasc Interv 2009;2(12): 1260-1265.

26. Kang S, Yang YJ, Xu B, et al. Comparison of drug eluting stents with bare metal stents in daily practice for bifurcation lesions in Chinese patients. Chin Med J (Engl) 2006;119(14):1157-1164.

27. Jonas M, Resnic FS, Levin AD, et al. Transition from bare metal to drug eluting stenting in contemporary US practice: Effect on incidence and predictors of clinically driven target le- sion revascularization. Catheter Cardiovasc Interv. 2007;70(2): 175-183.

28. Kim YH, Park SW, Lee CW, et al. Comparison of sirolimuseluting stent, paclitaxel-eluting stent, and bare metal stent in the treatment of long coronary lesions. Catheter Cardiovasc Interv 2006;67(2):181-187.

29. Alidoosti M, Salarifar M, Haji-Zeinali AM, et al. Clinical outcomes of drug-eluting stents compared with bare metal stents in our routine clinical practice. Hellenic J Cardiol 2008;49(3):132-138.

30. Xu B, Li JJ, Yang YJ, et al. A single center investigation of bare-metal or drug-eluting stent restenosis from 1633 consecutive Chinese Han ethnic patients. Chin Med J (Engl) 2006;119(7):533-538.

31. Bonello L, De Labriolle A, Lemesle G, et al. Comparison of outcomes of drug-eluting stents versus bare-metal stents in nonostial proximal left anterior descending coronary arteries. Am J Cardiol 2009;103(4):496-500.

32. Domínguez Franco AJ, Alonso Briales JH, Jiménez Navarro $\mathrm{MF}$, et al. Clinical impact of drug-eluting stents in an unselected population of diabetic patients. Clin Cardiol 2008;31(4):165171.

33. Gioia G, Matthai W, Benassi A, et al. Improved survival with drug-eluting stent implantation in comparison with bare metal stent in patients with severe left ventricular dysfunction. Catheter Cardiovasc Interv 2006;68(3):392-398.

34. Ortolani P, Balducelli M, Marzaroli P, et al. Two-year clinical outcomes with drug-eluting stents for diabetic patients with de novo coronary lesions: Results from a real-world multicenter registry. Circulation 2008;117(7):923-930. [Epub 2008 Feb].

35. Hamirani YS, Jibrin I, Abraham D, et al. Paclitaxel-eluting versus bare-metal stents in acute ST elevation myocardial infarction (STEMI). Crit Pathw Cardiol 2008;7(4):232-238.

36. Jensen J, Lagerqvist B, Aasa M, et al. Clinical and angiographic follow-up after coronary drug-eluting and bare metal stent implantation. Do drug-eluting stents hold the promise? J Intern Med 2006;260(2):118-124.

37. Onuma Y, Kukreja N, Piazza N, et al; Interventional Cardiologists of the Thoraxcenter (2000 to 2007). The everolimuseluting stent in real-world patients: 6-month follow-up of the X-SEARCH (Xience V Stent Evaluated at Rotterdam Cardiac Hospital) registry. J Am Coll Cardiol 2009;54(3): 269-276.

38. Pasceri V, Patti G, Pristipino C, et al. Safety of drug eluting stents in patients on chronic anticoagulation using long-term single antiplatelet treatment with clopidogrel. Catheter Cardiovasc Interv 2010;75(6):936-942.

39. Simsek C, Onuma Y, Magro M, et al; Interventional Cardiologists of the Thoraxcenter (2000-2005). Four-year clinical outcome of sirolimus- and paclitaxel-eluting stents compared to bare-metal stents for the percutaneous treatment of stable coronary artery disease. Catheter Cardiovasc Interv 2010;76(1): 41-46.

40. Singh IM, Filby SJ, El Sakr F, et al. Drug-eluting stents versus bare-metal stents for treatment of bare-metal in-stent restenosis. Catheter Cardiovasc Interv 2010;76(2):257-262.

41. Yan BP, Ajani AE, New G, et al; Melbourne Interventional Group Investigators. Are drug-eluting stents indicated in large coronary arteries? Insights from a multi-centre percutaneous coronary intervention registry. Int J Cardiol 2008;130(3):374 379. [Epub 2008 Aug 15].

42. Brodie BR, Wilson H, Stuckey T, et al; STENT Group. Outcomes with drug-eluting versus bare-metal stents in saphenous vein graft intervention results from the STENT (strategic transcatheter evaluation of new therapies) group. JACC Cardiovasc Interv 2009;2(11):1105-1112. 


\section{D’ASCENZO, ET AL.}

43. Ajani AE, Reid CM, Duffy SJ, et al. Outcomes after percutaneous coronary intervention in contemporary Australian practice: Insights from a large multicentre registry. Med J Aust 2008;189(8):423-428.

44. Applegate RJ, Sacrinty MT, Kutcher MA, et al. Comparison of drug-eluting versus bare metal stents on later frequency of acute myocardial infarction and death. Am J Cardiol 2007;99(3):333-338. [Epub 2006 Dec 1].

45. Bangalore S, Vlachos HA, Selzer F, et al. Percutaneous coronary intervention of moderate to severe calcified coronary lesions: Insights from the National Heart, Lung, and Blood Institute Dynamic Registry. Catheter Cardiovasc Interv 2011;77(1):22-28. doi: 10.1002/ccd.22613.

46. Brodie BR, Stuckey T, Downey W, et al; STENT (Strategic Transcatheter Evaluation of New Therapies) Group. Outcomes with drug-eluting stents versus bare metal stents in acute ST-elevation myocardial infarction: Results from the Strategic Transcatheter Evaluation of New Therapies (STENT) Group. Catheter Cardiovasc Interv 2008;72(7):893-900.

47. Dou KF, Xu B, Yang YJ, et al. Two-year clinical outcome after successful implantation of drug-eluting and bare metal stents in diabetic patients: Results from a real-world single center registry. Chin Med J (Engl) 2009;122(6):612-616.

48. Ferenc M, Gick M, Kienzle RP, et al. Long-term outcome of percutaneous catheter intervention for de novo coronary bifurcation lesions with drug-eluting stents or bare-metal stents. Am Heart J 2010;159(3):454-461.

49. Flores-Ríos X, Abugattás-de Torres JP, Campo-Pérez R, et al. Effect of stent thrombosis on the risk-benefit balance of drug-eluting stents and bare metal stents. Rev Esp Cardiol 2010;63(5):528-535.

50. Goswami NJ, Gaffigan M, Berrio G, et al. Long-term outcomes of drug-eluting stents versus bare-metal stents in saphenous vein graft disease: Results from the Prairie "Real World" Stent Registry. Catheter Cardiovasc Interv 2010;75(1):93100.

51. Gurvitch R, Lefkovits J, Warren RJ, et al. Clinical outcomes of drug-eluting stent use in patients with ST elevation myocardial infarction. Int J Cardiol 2010;143(3):283-288. [Epub 2009 Apr 2].

52. Kukreja N, Onuma Y, Garcia-Garcia HM, et al; Interventional Cardiologists of the Thoraxcenter (2000-5). Am J Cardiol 2009;103(2):203-211. [Epub 2008 Nov 19].

53. Marzocchi A, Saia F, Piovaccari G, et al. Long-term safety and efficacy of drug-eluting stents: Two-year results of the REAL (REgistro AngiopLastiche dell'Emilia Romagna) multicenter registry. Circulation 2007;115(25):3181-3188. [Epub 2007 Jun $11]$.

54. Ortolani P, Solinas E, Guastaroba P, et al. Long-term clinical outcomes after drug eluting stent implantation in women with de novo coronary lesions. Results from the REAL (REgistro Regionale AngiopLastiche Emilia-Romagna) multicenter registry. Int J Cardiol 2010 Jan 6. [Epub ahead of print].

55. Saia F, Piovaccari G, Manari A, et al. Patient selection to enhance the long-term benefit of first generation drug-eluting stents for coronary revascularisation procedures. Insights from a large multicentre registry. EuroIntervention 2009;5(1): $57-66$.

56. Varani E, Guastaroba P, Di Tanna GL, et al. Long-term clinical outcomes and cost-effectiveness analysis in multivessel percutaneous coronary interventions: Comparison of drug-eluting stents, bare-metal stents and a mixed approach in patients at high and low risk of repeat revascularisation. EuroIntervention 2010;5(8):953-961. doi: 10.4244/.

57. Austin D, Oldroyd KG, McConnachie A, et al. Drug-eluting stents versus bare-metal stents for off-label indications: A propensity score-matched outcome study. Circ Cardiovasc Interv 2008;1(1):45-52.

58. Applegate RJ, Sacrinty M, Kutcher M, et al. Late outcomes of drug-eluting versus bare metal stents in saphenous vein grafts: Propensity score analysis. Catheter Cardiovasc Interv 2008;72(1):7-12.

59. Alahmar AE, Grayson AD, et al. Reduction in mortality and target-lesion revascularisation at 2 years: A comparison between drug-eluting stents and conventional bare-metal stents in the "real world". Int J Cardiol 2009;132(3):398-404. [Epub 2008 Apr 24].

60. Gao RL, Xu B, Chen JL, et al. Two-year clinical outcomes following elective drug-eluting versus bare-metal stent implantation: Results from a large single-center database. Chin Med J (Engl). 2009;122(19):2261-2267.

61. Garg P, Normand SL, Silbaugh TS, et al. Drug-eluting or baremetal stenting in patients with diabetes mellitus: Results from the Massachusetts Data Analysis Center Registry. Circulation 2008;118(22):2277-2285, 7p following 2285. [Epub 2008 Nov 10].

62. Groeneveld PW, Matta MA, Greenhut AP, et al. Drug-eluting compared with bare-metal coronary stents among elderly patients. J Am Coll Cardiol 2008;51(21):2017-2024.

63. Kim KH, Koo BK, Min HS, et al. Comparison of drugeluting versus bare-metal stent implantation in ST-elevation myocardial infarction patients with renal insufficiency: Results from the national registry in Korea. Int J Cardiol 2012;154(1): 71-77.

64. Ko DT, Chiu M, Guo H, et al. Safety and effectiveness of drug-eluting and bare-metal stents for patients with off- and on-label indications. J Am Coll Cardiol 2009;53(19):17731782.

65. Ko DT, Chiu M, Austin PC, et al. Safety and effectiveness of drug-eluting stents among diabetic patients: A propensity analysis. Am Heart J 2008;156(1):125-134. [Epub 2008 May 6].

66. Mauri L, Silbaugh TS, Garg P, et al. Drug-eluting or baremetal stents for acute myocardial infarction. N Engl J Med 2008;359(13):1330-1342.

67. Mauri L, Silbaugh TS, Wolf RE, et al. Long-term clinical outcomes after drug-eluting and bare-metal stenting in Massachusetts. Circulation 2008;118(18):1817-1827. [Epub 2008 Oct 13].

68. Park KW, Kang SH, Chung WY, et al. 'Real world' comparison of drug-eluting stents vs bare metal stents in the treatment of unselected patients with acute ST-segment elevation myocardial infarction. Circ J 2010;74(6):1111-1120. [Epub 2010 Apr 20].

69. Ouldzein H, Roncalli J, Zouaoui W, et al. Drug-eluting or bare-metal stents in subjects over 75 years of age: What is the best therapeutic strategy? Data from 460 consecutive patients with 1-year outcome. Cardiovasc Revasc Med 2009;10(2): 94-102.

70. Roy P, Buch AN, Javaid A, et al. Impact of "off-label" utilization of drug-eluting stents on clinical outcomes in patients undergoing percutaneous coronary intervention. Am J Cardiol 2008;101(3):293-299. [Epub 2007 Dec 21].

71. Ruiz-Nodar JM, Marín F, Sánchez-Payá J, et al. Efficacy and safety of drug-eluting stent use in patients with atrial fibrillation. Eur Heart J 2009;30(8):932-939. [Epub 2009 Feb 26].

72. Tamburino C, Di Salvo ME, Capodanno D, et al. Are drugeluting stents superior to bare-metal stents in patients with unprotected non-bifurcational left main disease? Insights from a multicentre registry. Eur Heart J 2009;30(10):1171-1179. [Epub 2009 Mar 10]. 


\section{MULTIVARIABLE APPROACH IN DRUG-ELUTING STENT STUDIES}

73. Tu JV, Bowen J, Chiu M, et al. Effectiveness and safety of drugeluting stents in Ontario. N Engl J Med 2007;357(14):13931402.

74. Concato J, Peduzzi P, Holford TR, et al. Importance of events per independent variable in proportional hazards analysis. I. Background, goals, and general strategy. J Clin Epidemiol 1995;48:1495-1501.

75. Peduzzi P, Concato J, Feinstein AR, et al. Importance of events per independent variable in proportional hazards regression analysis. II. Accuracy and precision of regression estimates. J Clin Epidemiol 1995;48:1503-1510.

76. Hosmer DL, Lemeshow S. Applied Logistic Regression. New York: John Wiley and Sons, 2000.

77. Campbell EG, Rao SR, DesRoches CM, et al. Physician professionalism and changes in physician-industry relationships from 2004 to 2009. Arch Intern Med 2010;170(20): 1820-1826.

78. Harrington RA, Califf RM. There is a role for industrysponsored education in cardiology. Circulation 2010;121(20): 2221-2227.

79. Kirtane AJ, Gupta A, Iyengar S. Safety and efficacy of drugeluting and bare metal stents: Comprehensive meta-analysis of randomized trials and observational studies. Circulation 2009;119(25):3198-3206. [Epub 2009 Jun 15].

80. Roukoz H, Bavry AA, Sarkees ML, et al. Comprehensive metaanalysis on drug-eluting stents versus bare-metal stents during extended follow-up. Am J Med 2009;122(6):581.e1-10.

\section{Supporting Information}

Additional supporting information may be found in the online version of this article.

Table S1. Appendix Web Only Table

Please note: Wiley-Blackwell is not responsible for the content or functionality of any supporting materials supplied by the authors. Any queries (other than missing material) should be directed to the corresponding author for the article. 